\title{
EAGLES study: First-line Bevacizumab in Combination with Chemotherapy in Elderly Patients with Advanced, Metastatic, Non-squamous Non-small Cell Lung Cancer
}

\author{
FILIPPO DE MARINIS ${ }^{1}$, PAOLO BIDOLI ${ }^{2}$, ANDREA LUCIANI ${ }^{3}$, DOMENICO AMOROSO ${ }^{4}$, \\ GIUSEPPE TONINI $^{5}$, ALESSANDRO BERTOLINI $^{6}$, ALBA A. BRANDES $^{7}$, \\ MARIA RITA MIGLIORINO ${ }^{8}$, ADOLFO FAVARETTO $^{9}$ and CESARE GRIDELLI ${ }^{10}$ \\ ${ }^{I}$ Division of Thoracic Oncology, European Institute of Oncology (IEO), Milan, Italy; \\ ${ }^{2}$ Division of Medical Oncology, San Gerardo dei Tintori Hospital, Monza, Italy; \\ ${ }^{3}$ Medical Oncology, San Paolo Hospital, Milan, Italy; \\ ${ }^{4}$ Medical Oncology Unit, Versilia Hospital, Camaiore, Italy; \\ ${ }^{5}$ Medical Oncology Unit, Campus Bio-Medico University Hospital, Rome, Italy; \\ ${ }^{6}$ Medical Oncology Unit, Hospital of Sondrio, Sondrio, Italy; \\ ${ }^{7}$ Medical Oncology Department, AUSL-IRCCS Institute of Neurological Sciences, Bologna, Italy; \\ ${ }^{8}$ Unit of Thoracic Oncology, San Camillo Hospital, Rome, Italy; \\ ${ }^{9}$ Unit of Oncology, Ca' Foncello Hospital, Treviso, Italy; \\ ${ }^{10}$ Division of Medical Oncology, San Giuseppe Moscati Hospital, Avellino, Italy
}

\begin{abstract}
Background/Aim: The management of elderly patients with advanced non-squamous NSCLC includes several strategies. Patients and Methods: Patients ( $\geq 70$ years) were randomly assigned to bevacizumab $(7.5 \mathrm{mg} / \mathrm{kg}$ i.v. on day 1) plus gemcitabine $\left(1,200 \mathrm{mg} / \mathrm{m}^{2}\right.$ i.v. on days $\left.1-8\right)$ (arm A) or bevacizumab $\left(7.5 \mathrm{mg} / \mathrm{kg}\right.$ i.v.) and cisplatin $\left(60 \mathrm{mg} / \mathrm{m}^{2}\right.$ i.v.) plus gemcitabine $\left(1,000 \mathrm{mg} / \mathrm{m}^{2}\right.$ i.v. on days $\left.1-8\right)(\mathrm{arm} \mathrm{B})$, to independently evaluate treatments. The primary endpoint was progression-free rate at 6 months; secondary endpoints included progression-free survival (PFS) and safety profiles. Results: At 6 months, 5 (11.6\%) patients in arm $A$ and 5 patients (12.5\%) in arm B were found to be progression-free. Median PFS was 4.8 months in arm A and 6.5 months in arm $B$, respectively. Conclusion: In our experience, combination of bevacizumab and chemotherapy had encouraging antitumor efficacy as first-line therapy in elderly patients with non-squamous NSCLC.
\end{abstract}

This article is freely accessible online.

Correspondence to: Filippo de Marinis, MD, Ph.D., via Ripamonti 435, 20141 Milan, Italy. Tel: +39 0257489449. E-mail: filippo. demarinis@ieo.it

Key Words: Non-squamous non-small-cell lung cancer, elderly, bevacizumab, gemcitabine, cisplatin.
Lung cancer is the most common cancer worldwide and remains the leading cause of cancer-related deaths in Western countries (1). Non-small cell lung cancer (NSCLC) accounts for the wide majority of all lung cancers, with a frequency ranging from $80-85 \%$ of all diagnosed diseases (2). More than $50 \%$ of advanced NSCLCs patients are diagnosed at $>70$ years, and this tendency is likely to increase in the next years $(3,4)$. Elderly patients have a higher prevalence of comorbidities, higher risk for pharmacological interactions, and present an increased risk of mortality and toxicity with cancer treatments, compared to younger subjects (3). Moreover, elderly patients are often under-represented in clinical trials and therefore further indications for the management of NSCLC in this population seems required (3$5)$. The management of elderly patients with advanced NSCLC should be based upon the specific characteristics of each single patient, taking also into account the risk of toxicity associated with different therapeutic regimens $(6,7)$.

Bevacizumab (Avastin ${ }^{\circledR}$, Roche, Basel, Switzerland), an anti-vascular endothelial growth factor (VEGF) antibody, represents an established and effective therapy for nonsquamous NSCLC (8-10). Its use within combination regimens for the treatment of elderly non-squamous NSCLC patients has already been investigated both in prospective studies and in retrospective series (11-15). Despite this, additional evidence is required to draw a definite conclusions on the efficacy and safety of bevacizumab in this population. 
This multicenter, randomized, not comparative, phase II trial (EAGLES) investigates the efficacy and safety of bevacizumab in combination with gemcitabine or with gemcitabine plus attenuated doses of cisplatin in the firstline treatment of elderly patients with advanced, metastatic non-squamous NSCLC.

\section{Patients and Methods}

Setting. Seventeen Italian oncology Centers, distributed throughout the country, participated in the phase II EAGLES trial (Study No. ML21868). The study started in February 2010 and the last enrolment was in October 2013 (last safety evaluation: July 2014). The trial was conducted according to the Helsinki Declaration, and the local Ethical Committees approved the study protocol. All patients signed an informed consent before inclusion.

Patients. Eligibility for the patients was age $\geq 70$ years, stage IIIb (locally advanced, with supraclavicular lymph node metastases or malignant pleural or pericardial effusion) or stage IV (metastatic) nonsquamous NSCLC, inoperable condition as reported by histology or cytology. Other inclusion criteria were as follows: (i) at least one bidimensionally measurable lesion meeting RECIST criteria; (ii) Eastern Cooperative Oncology Group Performance Status (ECOG PS) of $0-1$; (iii) life expectancy $\geq 12$ weeks; (iv) adequate hematological function (absolute neutrophil count $\geq 1.5 \times 10^{9}$ and platelet count $\geq 100 \times 10^{9} / \mathrm{L}$ and hemoglobin $\geq 9 \mathrm{~g} / \mathrm{dl}$ [transfusions were allowed to maintain or exceed this level]), coagulation (international normalized ratio $[\mathrm{INR}] \leq 1.5$ and partial thromboplastin time [PTT or aPTT] $\leq 1.5 \times$ ULN within 7 days prior to enrolment), liver function (total bilirubin <1.5×ULN; aspartate aminotransferase [AST], alanine aminotransferase [ALT] $<2.5 \times$ ULN in patients without liver metastases or $<5 \times$ ULN in patients with liver metastases) and renal function (serum creatinine $\leq 1.25 \times \mathrm{ULN}$ or calculated creatinine clearance $\geq 50 \mathrm{ml} / \mathrm{min}$ and urine dipstick for proteinuria $<2+$ ).

Study design. This was an open-label, randomized, two-arm study. After screening, patients were randomly assigned, in a 1:1 ratio, to receive bevacizumab in combination with gemcitabine (treatment arm A) or bevacizumab in combination with gemcitabine and attenuated dose of cisplatin according to the MILES 2 study (treatment arm B(16) (Figure 1). Randomization was performed using ECOG performance status $(0,1)$ and stage (IIIb or IV) as stratification factors. Patients in arm A received bevacizumab $7.5 \mathrm{mg} / \mathrm{kg}$ i.v. on Day $1+$ gemcitabine $1,200 \mathrm{mg} / \mathrm{m}^{2} i . v$. on Days $1-8$ every 3 weeks, while patients in arm B received bevacizumab $7.5 \mathrm{mg} / \mathrm{kg}$ i.v. + cisplatin $60 \mathrm{mg} / \mathrm{m}^{2}$ i.v. on Day $1+$ gemcitabine $1,000 \mathrm{mg} / \mathrm{m}^{2}$ i.v. on Days $1-8$ every 3 weeks. Dose reductions and/or interruptions were allowed in the case of adverse events according to pre-defined protocols. Full supportive care was administered according to the standard practice of each center.

Treatment lasted for a maximum of six cycles until progression, death or intolerable toxicity, or withdrawal of consent. After this, patients continued maintenance treatment with bevacizumab $7.5 \mathrm{mg} / \mathrm{kg}$ every 21 days until progression, death or intolerable toxicity, or withdrawal of consent. Accountability and subject compliance were assessed by maintaining adequate drug dispensing records.

Patients were followed-up for 12 months after the last patient was enrolled or the last patient died (whichever occurred first), planned visits were every three months. End of study was planned to be at 15 months after the last patient was enrolled or until the last patient underwent death, disease progression, and intolerable toxicity or discontinued (whichever occurred first).

The primary endpoint was to evaluate the effects of bevacizumab + gemcitabine and bevacizumab + cisplatin + gemcitabine combinations by using progression-free rate (PFR) at 6 months. Patients who were not evaluated at this time, because of any reason, were considered as failures.

The secondary endpoints of this study were as follows: progression-free survival (PFS; defined as the interval between randomization and the first occurrence of progression or death from any cause); overall survival (OS; defined as the interval between randomization and death from any cause); 1-year survival rate (defined as the proportion of patients alive at 12 months after randomization); overall response rate (ORR; defined as the sum of complete response [CR] and partial response [PR] rates and considering the best response achieved); disease control rate (DCR; defined as the sum of CR, PR and stable disease [SD] rates) at 6 months; duration of response (defined as the interval from first occurrence of response to first occurrence of PD or death from any cause for patients who had achieved a response).

Safety assessment. About safety concern, type and severity of adverse events (AEs) were considered as well as physical examination, vital signs and laboratory test to evaluate the patient's condition.

Data provided by single investigators were used for merged analysis. Trained clinicians, who were blinded to treatment, evaluated tumor response according to the RECIST 1.1(17) criteria. Toxicity was graded according to the National Cancer Institute Common Terminology Criteria for AEs, version 3.0, by an Independent Data Safety Monitoring Board (DSMB) composed by three European clinicians with high level of experience in the management of NSCLC.

Statistical analysis. Evaluations were performed with an intent-to-treat basis (ITT population: all subjects randomized who received at least one dose of any medication), and results were presented overall and, for the primary endpoint, stratified by ECOG performance status ( 0 or 1) and by tumor stage (IIIb or IV). Survival functions were evaluated using the Kaplan-Meier method. All analyses for quantitative and qualitative variables were performed using SAS System software (version 9.2). All tests were two-sided with a significance level of 0.05 . All data were summarized by descriptive statistics.

It was expected that with chemotherapy, about $33 \%$ of elderly patients with PS 0-1 would have not progression at 6 months (18). Once defined P0 (minimum acceptable rate of patients without progression at 6 months) equivalent to $33 \%$ and P1 (auspicated acceptable rate of patients without progression at 6 months) to $53 \%$, with type 1 error $(\alpha)=0.10$ and type 2 error $(\beta)=0.10, P 0=0.33$ and $\mathrm{P} 1=0.53$, at least 39 patients were needed in each arm, with 17 patients progression free at 6 months, to define the result as conclusive.

\section{Results}

Patient characteristics and treatments. Eighty-six patients were enrolled: 44 were assigned to arm A and 42 to arm $\mathrm{B}$ (Figure 2). One patient in $\operatorname{arm} \mathrm{A}$ and two in $\operatorname{arm} \mathrm{B}$ did not receive any treatment and were not evaluated. Patients' and tumor characteristics are reported in Table I. 


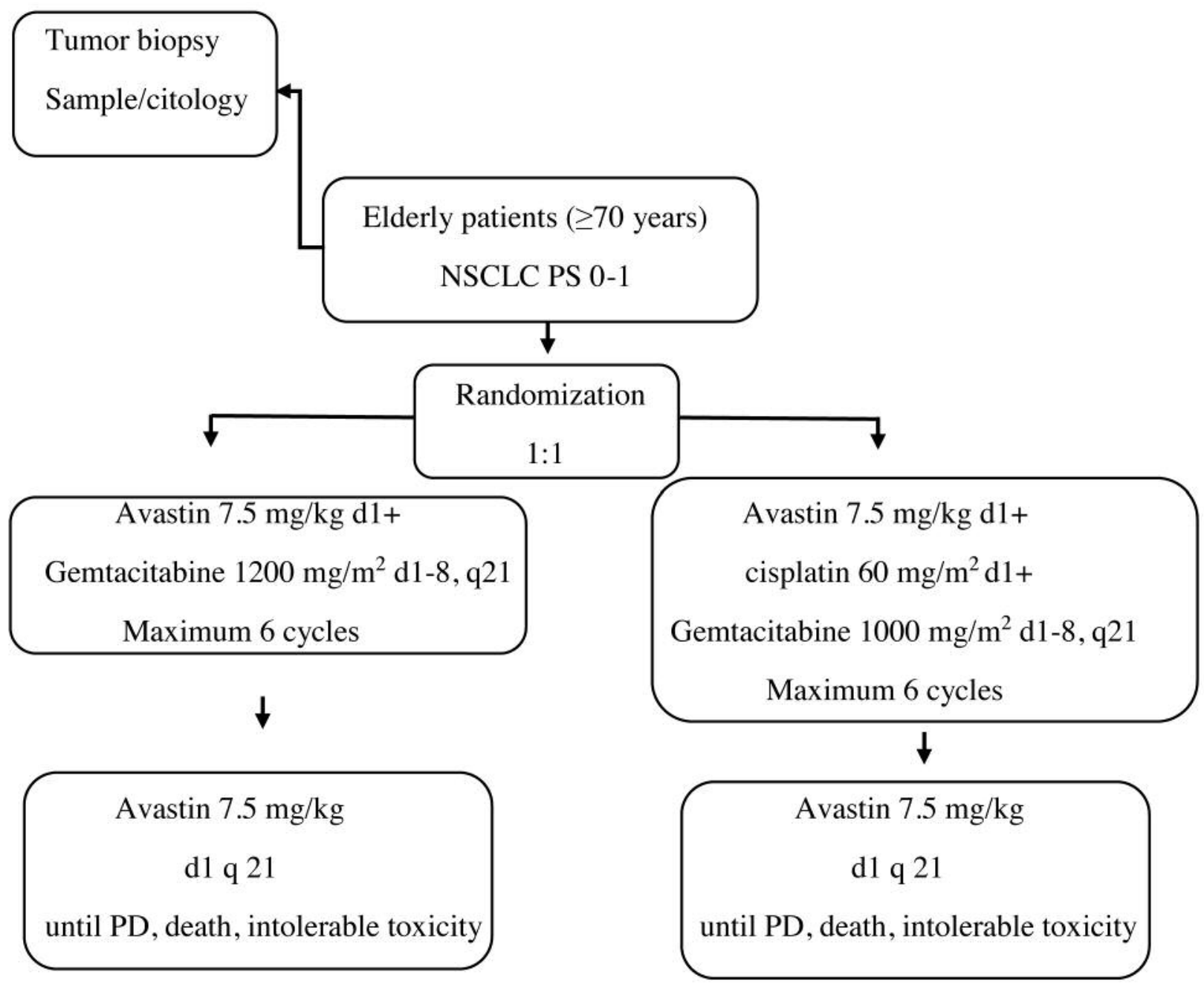

Figure 1. Study design.

Overall, there were no substantial differences between the two arms in demographic parameters and disease characteristics.

Twenty patients (46\% of treated) in arm A and 19 patients $(47 \%)$ in arm B completed the 6 cycles of treatment. The most common reasons for discontinuation of the 6-cycle treatment were $\mathrm{PD}$, with $10(23 \%)$ patients in arm A and 6 $(14 \%)$ patients in arm B, and AEs, with $7(16 \%)$ patients in arm A and $9(21 \%)$ patients in arm B.

Twelve patients $(60 \%$ of those who completed the 6 cycles) in arm A and $12(63 \%)$ in arm B received bevacizumab as maintenance treatment. The most common reason for discontinuation of maintenance bevacizumab in the follow-up period was PD, with 7 patients $(58 \%$ of those who received bevacizumab during the follow-up period) in arm A and $8(67 \%)$ patients in arm B, respectively.
Efficacy analysis. In total, 5 (11.6\%; 95\% CI: 2.1-21.2\%) patients in arm A and 5 (12.5\%; 95\% CI: 2.3-22.7\%) in arm $\mathrm{B}$ were progression-free at 6 months (Table II). In patients with ECOG $\mathrm{PS}=0$ (22 patients in arm $\mathrm{A}$ and 21 in arm $\mathrm{B}$ ), PFR was $22.7 \%(n=5 ; 95 \%$ CI: $5.2-40.2 \%)$ in arm $A$ and 19.0 ( $\mathrm{n}=4$; 95\% CI: $2.3-35.8 \%)$ in arm $\mathrm{B}$, while in patients with $\mathrm{PS}=1 \mathrm{PFR}$ was $0.0 \%$ and $5.3 \%(\mathrm{n}=1 ; 95 \% \mathrm{CI}: 0.0-$ $15.3 \%$ ), respectively. Median PFS was 4.8 months (95\% CI: 2.2-7.7 months) in arm A and 6.5 months (95\% CI: 4.5-9.9 months) in arm B. Eight (18.6\%) patients in arm A and 8 $(20.0 \%)$ in arm B were censored, while events were reported in $35(81.4 \%)$ patients in arm A and in $32(80.0 \%)$ in arm B, respectively. The HR $(95 \% \mathrm{CI})$ for PFS was $0.76(\mathrm{SE} \pm 0.24)$ for arm A versus arm B.

Median OS was 5.6 months (95\% CI: 3.4-13.0 months) in arm $\mathrm{A}$ and 12.0 months (95\% CI: 9.9-19.6 months) in 


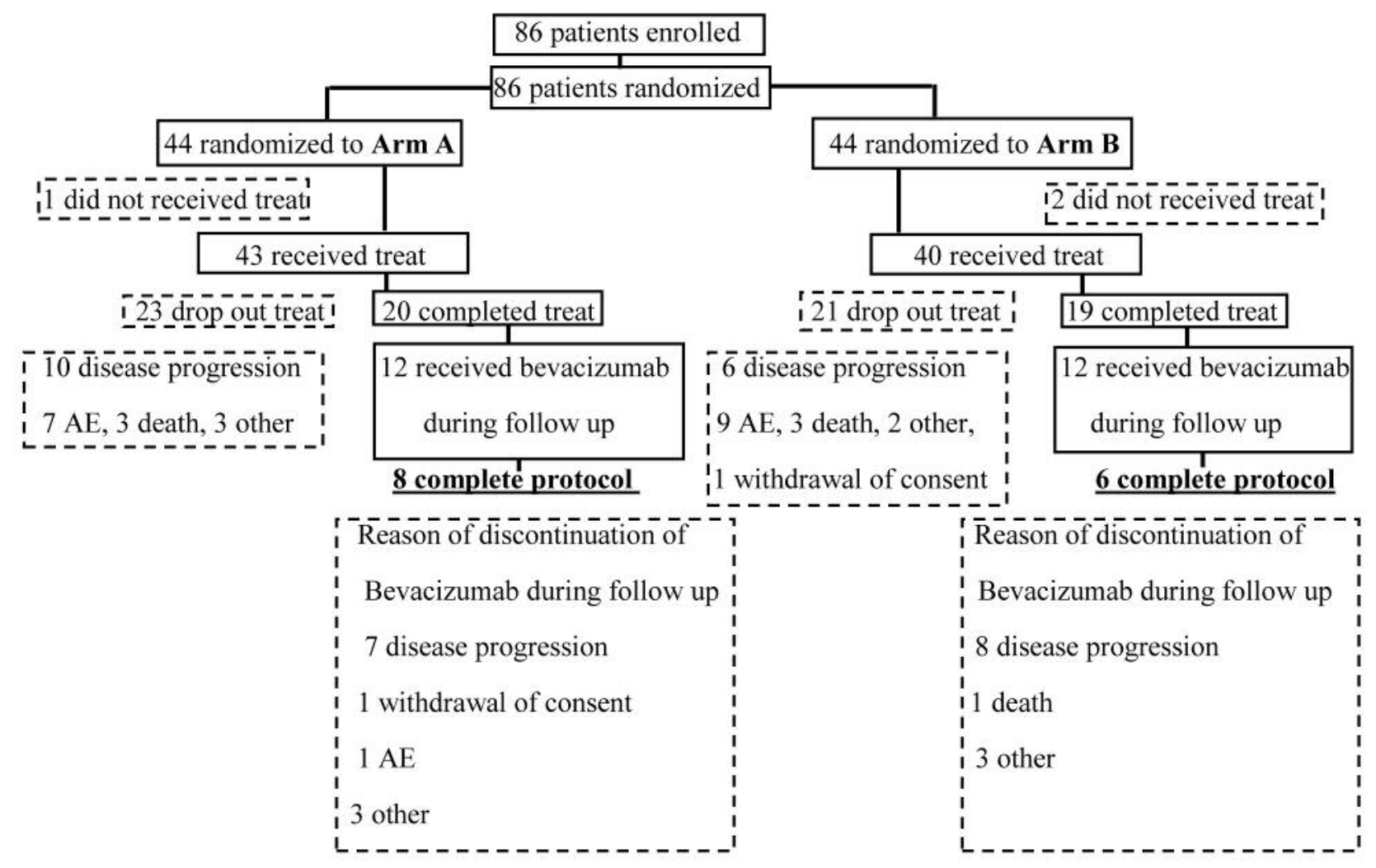

Figure 2. Patients' disposition. In Arm A, 36 patients did not complete protocol (28 deaths, 1 withdrawals of consent, 2 AEs, 1 lost in follow-up, 4 other reasons); in Arm B, 36 patients did not complete protocol (29 deaths, 2 withdrawals of consent, 1 AE, 1 lost in follow-up, 2 other reasons). $A E$ : Adverse event.

arm B (Figure 3). Thirteen (30.2\%) patients in arm A and $11(32.5 \%)$ in arm B were censored, while deaths occurred in $30(69.8 \%)$ patients in arm A and in $29(72.5 \%)$ in arm B. Sixteen (37.2\%; 95\% CI: 22.8-51.7\%) patients in arm A and 19 (47.5\%; 95\% CI: 32.0-63.0\%) in arm B were alive at one year.

The majority of patients $(n=27,62.8 \%$ in arm $A$ and $n=16$, $40.0 \%$ in arm B) was not evaluable for response. The ORR was $18.6 \%$ (95\% CI: $6.9-30.2 \%)$ in arm A and $35.0 \%(95 \%$ CI: $20.2-49.8 \%)$ in arm $B$; all responding patients $(n=8$ and $\mathrm{n}=14$, respectively) experienced a PR. Five $(11.6 \% ; 95 \% \mathrm{CI}$ : $2.0-21.2 \%)$ patients in arm A and $8(20.0 \%$; $95 \%$ CI: $7.6-$ $32.4 \%$ ) in arm B achieved SD. DCR at six months was $11.6 \%(\mathrm{n}=5 ; 95 \%$ CI: $2.0-21.2 \%)$ in arm $\mathrm{A}$ and $12.5 \%(\mathrm{n}=5$; 95\% CI: $2.2-22.7 \%$ ) in arm B.

Median duration of response was 6.9 months $(95 \% \mathrm{CI}$ : 3.0-11.7 months) in arm A and 5.6 months (95\% CI: 2.6-8.8 months) in arm B. Two (4.65\%) patients in arm A and 1 $(2.5 \%)$ in arm B were censored, while progressions/deaths were reported in $6(14.0 \%)$ patients in arm A and in 13 $(32.5 \%)$ patients in arm $\mathrm{B}$, respectively.
Safety. Apart from one patient in both arms, all patients experienced at least one AE. The rate of patients with treatment-related AEs was higher in arm B (35 patients, $87.5 \%)$ than in arm A (30 patients, 69.8\%). More patients in arm B (29 patients, 72.5\%) than in arm A (19 patients, $44.2 \%$ ) had AEs related to bevacizumab; similarly, more patients in arm B (34 patients, 85.0\%) than in arm A (26 patients, $60.5 \%$ ) experienced AEs related to gemcitabine. AEs related to cisplatin were reported in 34 patients $(85.0 \%)$.

The most commonly reported AEs were, in order, neutropenia ( $\operatorname{arm} \mathrm{A}: \mathrm{n}=11,25.6 \%$; $\operatorname{arm} \mathrm{B}: \mathrm{n}=21,52.5 \%$ ), nausea (arm A: $n=6,14.0 \%$; arm $B: n=15,37.5 \%$ ) and thrombocytopenia ( $\operatorname{arm} \mathrm{A}: \mathrm{n}=5,11.6 \%$; $\operatorname{arm} \mathrm{B}: \mathrm{n}=15,37.5 \%$ ). The proportion of patients with severe AEs was higher in arm A $(n=17,39.5 \%)$ than in arm B $(n=10,25.0 \%)$ (Table III).

Overall, the incidence of AEs during the maintenance period was lower than that during the treatment period (data not shown). Fatal AEs occurred in 8 patients (18.6\%) in arm $\mathrm{A}$ and in 4 patients $(10.0 \%)$ in arm B, with 2 (embolism, cardiac failure) and 1 events (pulmonary hemorrhage) considered treatment-related. 
Table I. Patient baseline and tumor characteristics.

\begin{tabular}{|c|c|c|}
\hline & $\begin{array}{l}\text { Arm A } \\
(\mathrm{N}=43)\end{array}$ & $\begin{array}{l}\text { Arm B } \\
(\mathrm{N}=40)\end{array}$ \\
\hline Age (years), mean \pm SD & $74.2 \pm 3.2$ & $73.9 \pm 3.5$ \\
\hline \multicolumn{3}{|l|}{ Gender, N (\%) } \\
\hline Males & $27(62.8 \%)$ & $28(70.0 \%)$ \\
\hline Females & $16(37.2 \%)$ & $12(30.0 \%)$ \\
\hline \multicolumn{3}{|l|}{ ECOG PS, N (\%) } \\
\hline 0 & $22(51.2 \%)$ & $21(52.5 \%)$ \\
\hline 1 & $21(48.8 \%)$ & $19(47.5 \%)$ \\
\hline \multicolumn{3}{|l|}{ Tumor characteristics at first diagnosis } \\
\hline \multicolumn{3}{|l|}{ Stage at inclusion, $\mathrm{N}(\%)$} \\
\hline IIIb & $4(9.3 \%)$ & $1(2.5 \%)$ \\
\hline IV & $39(90.7 \%)$ & $39(97.5 \%)$ \\
\hline \multicolumn{3}{|l|}{ Method of diagnosis, $\mathrm{N}(\%)$} \\
\hline Histology & $25(58.1 \%)$ & $27(67.5 \%)$ \\
\hline Cytology & $15(34.9 \%)$ & $8(20.0 \%)$ \\
\hline Both & $3(7.0 \%)$ & $4(10.0 \%)$ \\
\hline Unknown & $0(0.0 \%)$ & $1(2.5 \%)$ \\
\hline \multicolumn{3}{|l|}{ Histological types, $\mathrm{N}(\%)$} \\
\hline Adenocarcinoma & $35(81.4 \%)$ & $36(90.0 \%)$ \\
\hline Large cells carcinoma & $1(2.3 \%)$ & $3(7.5 \%)$ \\
\hline Bronchoalveolar & $0(0.0 \%)$ & $0(0.0 \%)$ \\
\hline Mixed cell type ( $>50 \%$ nonsquamous) & $0(0.0 \%)$ & $0(0.0 \%)$ \\
\hline Other (large cells, poorly differentiated, lepidic growth) & $7(16.3 \%)$ & $1(2.5 \%)$ \\
\hline \multicolumn{3}{|l|}{ Centrally located lung tumor $\mathrm{N}(\%)$} \\
\hline No & $25(58.1 \%)$ & $21(52.5 \%)$ \\
\hline Yes & $18(41.9 \%)$ & $19(47.5 \%)$ \\
\hline \multicolumn{3}{|l|}{ Cavitation $\mathrm{N}(\%)$} \\
\hline No & $41(95.3 \%)$ & $36(90.0 \%)$ \\
\hline Yes & $2(4.7 \%)$ & $4(10.0 \%)$ \\
\hline Time from diagnosis (months), mean \pm SD & $1.2 \pm 1.4$ & $1.0 \pm 0.9$ \\
\hline
\end{tabular}

Table II. Progression-free rate at 6 months.

\begin{tabular}{lcc}
\hline & $\begin{array}{c}\text { Arm A } \\
(\mathrm{N}=43)\end{array}$ & $\begin{array}{c}\text { Arm } \mathrm{B} \\
(\mathrm{N}=40)\end{array}$ \\
\hline Progression at 6 months, $\mathrm{N}(\%)[95 \% \mathrm{CI}]$ & & \\
$\quad$ Progression-free & $5(11.6 \%)[2.1-21.2 \%]$ & $5(12.5 \%)[2.3-22.7 \%]$ \\
$\quad$ Non progression-free & $38(88.4 \%)[78.8-98.0 \%]$ & $35(87.5 \%)[77.3-97.7 \%]$ \\
\hline
\end{tabular}

All patients that did not reach or did not perform the observation at 6 months (due to any reason) were considered as failures.

\section{Discussion}

The treatment of elderly patients with advanced nonsquamous NSCLC remains a matter of debate. Targeted angiogenesis can lead to regression or normalization of newly-formed vessels (10). To achieve this goal, the VEGF inhibition, exerted by bevacizumab, the only anti-angiogenic agent currently approved for the first-line treatment of non- squamous NSCLC, is the most commonly used strategy (10). However, the efficacy and safety of bevacizumab in elderly patients has only been poorly explored to date, with conflicting results (11-15). For example, in the subgroup analysis of the 224 elderly patients enrolled in the ECOG 4599 , the addition of bevacizumab did not result in a significant survival, but it was associated with an increased toxicity (more grade 4 neutropenia, melena and 


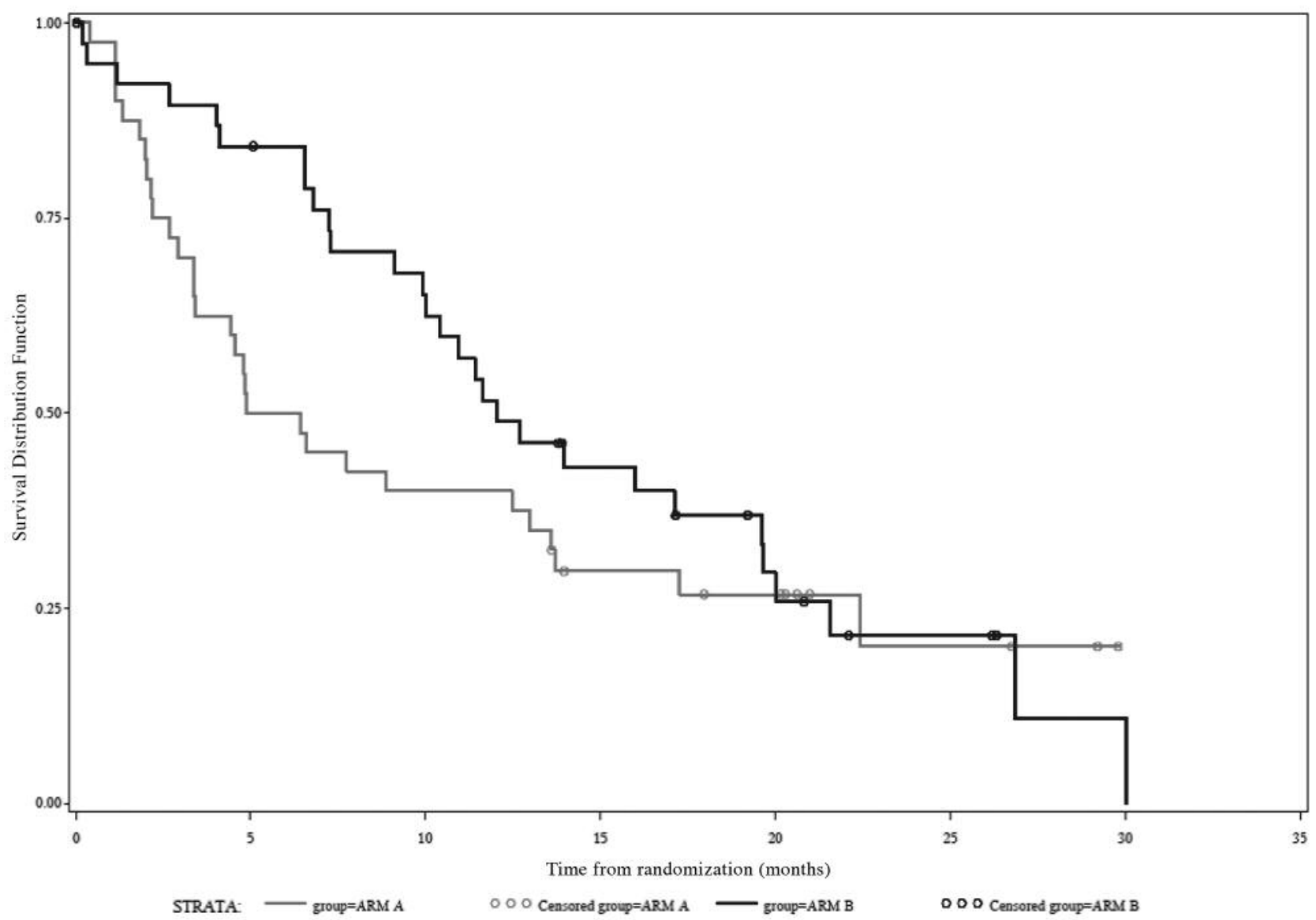

Figure 3. Kaplan-Meier analysis of overall survival.

gastrointestinal bleeding, muscle weakness, motor neuropathy) compared with younger counterparts (14). On the other hands, a recent exploratory subgroup analysis of patients enrolled in 2 randomized trials suggests that survival benefit for bevacizumab added to chemotherapy likely would be limited to patients aged less than 75 years, although the small number of subjects in this subgroup precludes firm conclusions (18).

The present multicenter study aimed at specifically investigating the use of bevacizumab in combination with either gemcitabine or gemcitabine + attenuated-dose cisplatin in non-squamous NSCLC patients aged 70 years or older. In this study, the progression-free rate at 6 months was lower than expected. PFRs were similar in the two arms of treatment, $11.6 \%$ in arm A and $12.5 \%$ in arm B; comparable results in PFR were obtained also when patients were stratified according to ECOG PS or tumor stage. On the other hand, PFS and OS were longer in arm B than in arm A, potentially suggesting a more efficacy of the bevacizumab+attenuated cisplatin+gemcitabine regimen. Notably, patients assigned to arm B experienced a higher rate of response, although DCR at 6 months was comparable between the two arms.

A recent meta-analysis showed no difference in bevacizumab efficacy according to the chemotherapy regimen used (20). However, in order to explain our results, we should debate on gemcitabine-based chemotherapy, which probably is not the best companion for bevacizumab (21), that obtained the best results in addition to carboplatin plus paclitaxel regimen (11).

Safety is a major concern when treating elderly patients $(22,23)$. In the present study, both treatment regimens were associated with an overall favorable safety profile, with low incidence of severe adverse events (AEs) as assessed by a DSMB composed by experienced clinicians. No unexpected toxicity concerns were documented. Only three fatal treatment-related AEs were reported, but they occurred in patients who were particularly frail and/or underwent major protocol violations. This favorable safety profile was also observed during the maintenance phase, when patients were on bevacizumab only. 
Table III. Most commonly reported adverse events by preferred term (i.e. adverse events reported in $\geq 5 \%$ of patients in any arm). Data are expressed as number of patients (\%) [number of events].

\begin{tabular}{lcc}
\hline Event & $\begin{array}{c}\text { Arm A } \\
(\mathrm{N}=43)\end{array}$ & $\begin{array}{c}\text { Arm B } \\
(\mathrm{N}=40)\end{array}$ \\
\hline Abdominal pain upper & $0(0.0 \%)[0]$ & $2(5.0 \%)[2]$ \\
Anaemia & $4(9.3 \%)[4]$ & $12(30.0 \%)[34]$ \\
Asthenia & $2(4.7 \%)[3]$ & $6(15.0 \%)[10]$ \\
Blood creatinine increased & $0(0.0 \%)[0]$ & $4(10.0 \%)[9]$ \\
Constipation & $1(2.3 \%)[1]$ & $5(12.5 \%)[5]$ \\
Diarrhoea & $1(2.3 \%)[1]$ & $3(7.5 \%)[4]$ \\
Dizziness & $0(0.0 \%)[0]$ & $2(5.0 \%)[2]$ \\
Dyspnoea & $0(0.0 \%)[0]$ & $2(5.0 \%)[2]$ \\
Embolism & $2(4.7 \%)[2]$ & $6(15.0 \%)[8]$ \\
Epistaxis & $1(2.3 \%)[2]$ & $2(5.0 \%)[2]$ \\
Fatigue & $4(9.3 \%)[5]$ & $12(30.0 \%)[29]$ \\
Haemoptysis & $4(9.3 \%)[4]$ & $4(10.0 \%)[4]$ \\
Hyperkalemia & $0(0.0 \%)[0]$ & $2(5.0 \%)[3]$ \\
Hypertension & $8(18.6 \%)[10]$ & $5(12.5 \%)[7]$ \\
Leukopenia & $2(4.7 \%)[9]$ & $11(27.5 \%)[39]$ \\
Mucosal inflammation & $1(2.3 \%)[1]$ & $3(7.5 \%)[4]$ \\
Nausea & $6(14.0 \%)[10]$ & $15(37.5 \%)[30]$ \\
Neutropenia & $11(25.6 \%)[24]$ & $21(52.5 \%)[58]$ \\
Platelet count decreased & $3(7.0 \%)[3]$ & $4(10.0 \%)[9]$ \\
Proteinuria & $4(9.3 \%)[5]$ & $0(0.0 \%)[0]$ \\
Thrombocytopenia & $5(11.6 \%)[8]$ & $15(37.5 \%)[48]$ \\
Vomiting & $3(7.0 \%)[5]$ & $4(10.0 \%)[6]$ \\
\hline
\end{tabular}

In conclusion, although our study did not meet its primary endpoint, the results may pave the way for other studies specifically aiming at investigating the efficacy and safety of oncological treatment in elderly population, usually excluded from pivotal clinical trials and for whom only few evidence is available. In particular, addition of bevacizumab to different chemotherapy regimens (i.e. carboplatin + paclitaxel, carboplatin + nab-paclitaxel, carboplatin + pemetrexed) in advanced non-squamous NSCLC elderly patients could be investigated in upcoming clinical trial.

\section{Funding}

Roche S.p.A, Monza, Italy, funded the study.

\section{Acknowledgements}

The Authors would like to thank all the other EAGLES investigators: O. Alabisio, E. Arnoldi, P. Rosetti, G. Fasola, A. Bearz, H. Soto Parra, L. Crinò and E.M. Ruggeri. The Authors also thank the DSMB Members (Prof. Thatcher, UK; Prof. Stahel, Switzerland; Dr. Galimberti, Italy) and the central assessors of tumor response (M. Rinaldi and M. Caterino). Content Ed Net provided editorial assistance in drafting manuscript.

\section{References}

1 Ferlay J, Soerjomataram I, Dikshit R, Eser S, Mathers C, Rebelo M, Parkin DM, Forman D and Bray F: Cancer incidence and mortality worldwide: sources, methods and major patterns in GLOBOCAN 2012. Int J Cancer 136: E359-386, 2015.

2 Siegel R, Ma J, Zou Z and Jemal A: Cancer statistics, 2014. CA Cancer J Clin 64: 9-29, 2014.

3 Sacco PC, Maione P, Rossi A, Sgambato A, Casaluce F, Palazzolo $G$ and Gridelli $C$ : New antiangiogenetic therapy beyond bevacizumab in the treatment of advanced non small cell lung cancer. Curr Pharm Des 21: 4763-4772, 2015.

4 Gridelli C, Balducci L, Ciardiello F, Di Maio M, Felip E, Langer C, Lilenbaum RC, Perrone F, Senan S and de Marinis F: Treatment of Elderly Patients With Non-Small-Cell Lung Cancer: Results of an International Expert Panel Meeting of the Italian Association of Thoracic Oncology. Clin Lung Cancer 16: 325-333, 2015

5 Gridelli C, Maione P, Rossi A, Ferrara ML, Castaldo V, Palazzolo $\mathrm{G}$ and Mazzeo N: Treatment of advanced non-smallcell lung cancer in the elderly. Lung Cancer 66: 282-286, 2009.

6 Reck M, Popat S, Reinmuth N, De Ruysscher D, Kerr KM and Peters S; ESMO Guidelines Working Group: Metastatic nonsmall-cell lung cancer (NSCLC): ESMO Clinical Practice Guidelines for diagnosis, treatment and follow-up. Ann Oncol 25: iii27-39, 2014.

7 Masters GA, Temin S, Azzoli CG, Giaccone G, Baker S Jr., Brahmer JR, Ellis PM, Gajra A, Rackear N, Schiller JH, Smith TJ, Strawn JR, Trent D and Johnson DH; American Society of Clinical Oncology: Clinical Practice Systemic Therapy for Stage IV Non-Small-Cell Lung Cancer: American Society of Clinical Oncology Clinical Practice Guideline Update. J Clin Oncol 33(30): 3488-3515, 2015.

8 Keating GM: Bevacizumab: a review of its use in advanced cancer. Drugs 74(16): 1891-1925, 2014

9 Liu KJ, Ding LY and Wu HY: Bevacizumab in combination with anticancer drugs for previously treated advanced non-small cell lung cancer. Tumour Biol 36(3): 1323-1327, 2015.

10 Lauro S, Onesti CE, Righini R and Marchetti P: The use of bevacizumab in non-small cell lung cancer: an update. Anticancer Res 34(4): 1537-1545, 2014.

11 Sandler A, Gray R, Perry MC, Brahmer J, Schiller JH, Dowlati A, Lilenbaum R and Johnson DH: Paclitaxel-carboplatin alone or with bevacizumab for non-small-cell lung cancer. $\mathrm{N}$ Engl $\mathrm{J}$ Med 355: 2542-2550, 2006.

12 Dy GK, Molina JR, Qi Y, Ansari R, Thomas S, Ross HJ, Soori G, Anderson D, Aubry MC, Meyers J, Adjei AA, Mandrekar S and Adjei AA: NCCTG N0821 (Alliance): a phase II first-line study of pemetrexed, carboplatin, and bevacizumab in elderly patients with advanced nonsquamous non-small-cell lung cancer with good performance status. J Thorac Oncol 9: 1146-1153, 2014.

13 Laskin J, Crinò L, Felip E, Franke F, Gorbunova V, Groen H, Jiang GL, Reck M and Schneider CP: Safety and efficacy of first-line bevacizumab plus chemotherapy in elderly patients with advanced or recurrent nonsquamous non-small cell lung cancer: safety of avastin in lung trial (MO19390). J Thorac Oncol 7: 203-211, 2012.

14 Ramalingam SS, Dahlberg SE, Langer CJ, Gray R, Belani CP, Brahmer JR, Sandler AB, Schiller JH, Johnson DH and Eastern Cooperative Oncology Group: Outcomes for elderly, advanced- 
stage non small-cell lung cancer patients treated with bevacizumab in combination with carboplatin and paclitaxel: analysis of Eastern Cooperative Oncology Group Trial 4599. J Clin Oncol 26: 60-65, 2008 .

15 Zhu J, Sharma DB, Gray SW, Chen AB, Weeks JC and Schrag D: Carboplatin and paclitaxel with vs without bevacizumab in older patients with advanced non-small cell lung cancer. JAMA 307: 1593-1601, 2012.

16 Gridelli C, Maione P, Illiano A, Piantedosi FV, Favaretto A, Bearz A, Robbiati SF, Filipazzi V, Lorusso V, Carrozza F, Iaffaioli RV, Manzione L, Gallo C, Morabito A and Perrone F: Cispaltin plus gemcitabine or vonorelbine for elderly patients with advanced non-small cell lung cancer: The MILES-2P studies. J Clin Oncol 25: 4663-4669, 2007.

17 Eisenhauer EA, Therasse P, Bogaerts J, Schwartz LH, Sargent D, Ford R, Dancey J, Arbuck S, Gwyther S, Mooney M, Rubinstein L, Shankar L, Dodd L, Kaplan R, Lacombe D and Verweij J: New response evaluation criteria in solid tumours: Revised RECIST guideline (version 1.1). Eur J Cancer 45: 228247, 2009.

18 Gridelli C, Perrone F, Gallo C, Cigolari S, Rossi A, Piantedosi F, Barbera S, Ferraù F, Piazza E, Rosetti F, Clerici M, Bertetto O, Robbiati SF, Frontini L, Sacco C, Castiglione F, Favaretto A, Novello S, Migliorino MR, Gasparini G, Galetta D, Iaffaioli RV, Gebbia V and MILES Investigators: Chemotherapy for elderly patients with advanced non-small-cell lung cancer: the Multicenter Italian Lung Cancer in the Elderly Study (MILES) phase III randomized trial. J Natl Cancer Inst 95: 362-372, 2003.

19 Langer CJ, Socinski MA, Patel JD, Sandler AB, Schiller JH, Leon L, Hazard SJ and Ramalingam SS: Isolating the role of bevacizumab in elderly patients with previously untreated nonsquamous non-small cell lung cancer: secondary analyses of the ECOG 4599 and PointBreak trials. Am J Clin Oncol 39(5): 441-447, 2016.
20 Behera M, Pillai RN, Owonikoko TK, Kim S, Steuer C, Chen Z, Saba NF, Belani CP, Khuri FR and Ramalingam SS: Bevacizumab in combination with taxane versus non-taxane containing regimens for advanced/metastatic non-squamous nonsmall-cell lung cancer: a systematic review. J Thorac Oncol 10: 1142-1147, 2015.

21 Reck M, von Pawel J, Zatloukal P, Ramlau R, Gorbounova V, Hirsh V, Leighl N, Mezger J, Archer V, Moore N and Manegold C: BO17704 Study Group. Overall survival with cisplatin/gemcitabine and bevacizumab or placebo as first-line therapy for nonsquamous non-small cell lung cancer: results from a randomized phase III trial (AVAiL). Ann Oncol 21: 1804-1809, 2010.

22 Mohile SG, Hardt M, Tew W, Owusu C, Klepin H, Gross C, Gajra A, Lichtman SM, Feng T, Togawa K, Ramani R, Katheria V, Hansen K, Hurria A and Cancer and Aging Research Group: Toxicity of bevacizumab in combination with chemotherapy in older patients. Oncologist 18: 408-414, 2013.

23 van Veggel BA, Biesma B and Smit EF: Pharmacotherapy for treatment of lung cancer in the elderly Expert Opin Pharmacother 16: 1021-1234, 2015.
Received March 23, 2017

Revised April 6, 2017

Accepted April 10, 2017 